\title{
Papillon lefevre syndrome- A literature review and case report
}

\author{
Lashika V Tambe ${ }^{*}$, Mala Dixit ${ }^{2}$, Nikita Patil ${ }^{3}$ \\ ${ }^{\mathbf{1}}$ Assistant Professor, ${ }^{2}$ Professor and Head, ${ }^{3}$ Post Graduate, Dept. of Periodontology, ${ }^{\mathbf{1}}$ Government Dental College and Hospital, Mumbai, \\ Maharashtra, ${ }^{2,3}$ Nair Hospital Dental College, Mumbai, Maharashtra, India \\ *Corresponding Author: Lashika V Tambe \\ Email: lashika.tambe@gmail.com
}

\begin{abstract}
Papillon-Lefèvre syndrome (PLS) is an extremely rare genetic disorder. This disorder is mostly observed in children from 1-5 years of age. Alteration of CTSC gene which regulates the production of enzyme cathepsin $\mathrm{C}$ is responsible for this syndrome. The common characteristics are palmoplantar keratosis and aggressive form of periodontitis. The patient might become completely edentulous in the absence of appropriate and early treatment. Early lose of teeth in young children may have two important concerns- 1. Pychological impact. 2. Prosthetic rehabilitation. Till date, there is no definitive treatment protocol for PLS cases. This article provides a detailed review about the various possible etiologies, clinical features, differential diagnosis and treatment protocols followed for the periodontal management of PLS. This article reports a Case of Papillon Lefèvre syndrome and its management with long term follow up.
\end{abstract}

Keywords: Periodontitis, Papillon Lefevre syndrome.

\section{Introduction}

Papillon-Lefèvre syndrome (PLS) is a rare autosomal recessive heterogeneous disorder. Gorlin RJ et al (1964) stated that "The common characteristics of PLS are palmoplantar hyperkeratosis, early loss of primary and permanent teeth, and associated calcification of the dura mater". ${ }^{1}$ It was first described in 1924 by French physicians Papillon and Lefèvre. ${ }^{2}$ The PLS syndrome is extremely rare and is observed in one in 4 million cases. Its equally seen in both males and females. Also it is equally distributed among all the human races. There has always been a dilemma regarding the etiology of this syndrome. However, PLS can be hereditary, acquired or even associated with other genetic disorders. Hart et al (1994) stated "If both parents are carriers of the defective gene there is a $25 \%$ risk for their children to be affected". ${ }^{3-7}$ Hart TC et al (1999) stated that "Mutation of the cathepsin $\mathrm{C}$ gene are responsible for Papillon-Lefèvre syndrome". PLS results from genetic mutations on both alleles of the cathepsin C gene (CTSC) on chromosome 11q14.2. ${ }^{8}$ This article reports a complete case of this rare syndrome, Papillon-Lefèvre syndrome.

\section{Case Report}

A 12-year-old boy, visited to our department of Periodontology with chief complaint of early loss of deciduous teeth, mobility of teeth and sensitivity of teeth on drinking cold water. He first noticed mobility in his teeth 2 years back, since then it gradually increased. He also complaint of bleeding from his gums since 2 years. The bleeding aggravates while brushing teeth in the morning.

A thorough medical and family history was taken for the patient.

He was the first child born to healthy consanguineous parents. History revealed that his deciduous teeth had erupted normally. However they exfoliated gradually by the age of 5 years. Early loss of teeth made it very difficult for him to chew food. This further led to loss of apatite and eventually weight loss.

\section{Clinical Features \\ Intra-oral findings}

Intra-oral examination revealed severely inflamed red colour gingiva. Spontaneous bleeding from the gingiva was seen on probing the gingival sulcus throughout the oral cavity. The consistency of the gingiva was soft and edematous. Teeth 44 , 32 and 35 were missing. Severe bone loss resulted in pathological migration of teeth $11,21,31$ and 41 . On assessment, grade III mobility was present in relation with 36 and 46 , grade II in relation with 31 and 41 . Remaining teeth were present with grade I mobility. There were periodontal pockets of $8-9 \mathrm{~mm}$ with respect to 36 and 46 and periodontal pockets of $4-5 \mathrm{~mm}$ with respect to the remaining teeth. [Fig. 1 $a, b, c]$

\section{Extra-oral findings}

On extra-oral examination, patient presented with welldemarcated, dry, scaly, keratotic plaques over the skin of palms, elbows and soles extending on to the dorsal surfaces.[Fig. 2 a,b,c]

\section{Radiographic findings}

Orthopantomogram showed more than $50 \%$ bone loss in the posterior teeth especially in 36 and 46 teeth region. All the third molars were impacted with incomplete root formation. [Fig. 3]

\section{Investigations}

All biochemical investigations was done for the patientComplete blood count test, Liver function test, urine analysis and Alkaline phosphatse levels were normal.

Patient was referred for Genetic test (Constitutional Karyotyping) which came to be negative.

\section{Management}

Papillon Lefèvre patient requires a multi-disciplinary approach for dental and dermatological treatment. The patient was referred to a Dermatologist for his skin lesions. The dental treatment which included aggressive form of periodontitis was managed by the Periodontist. 

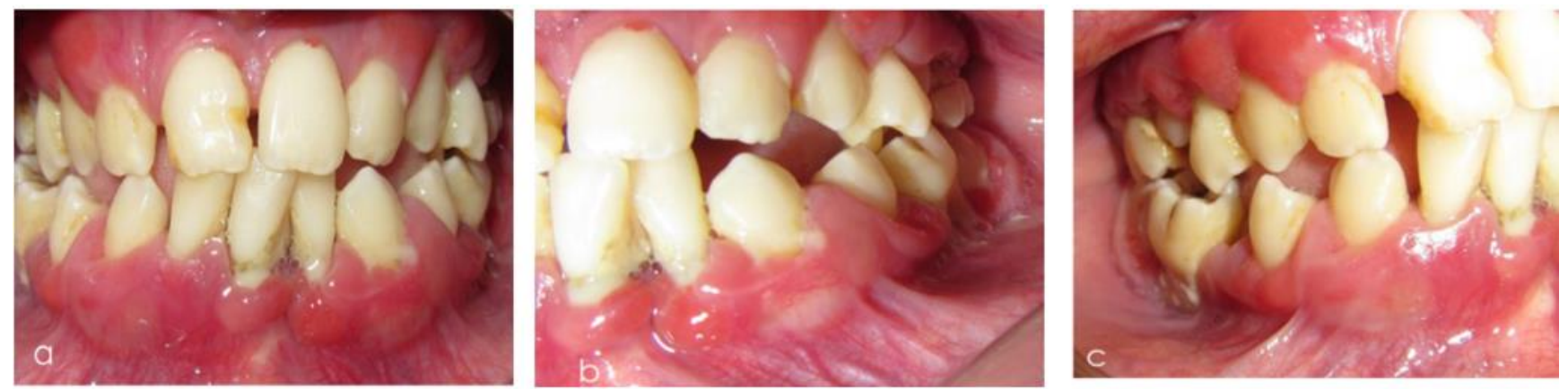

Fig. 1: Pre-operative intra oral findings
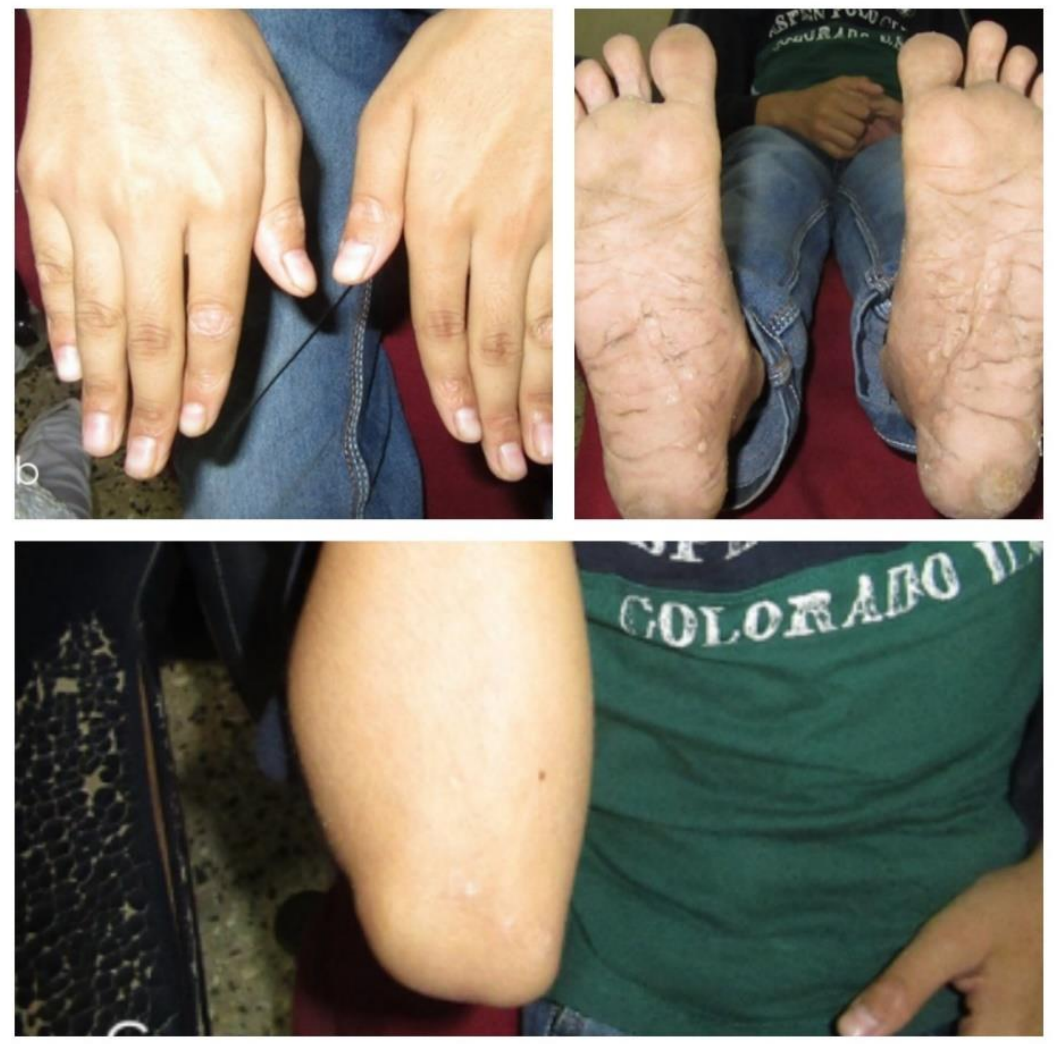

Fig. 2: Preoperative extra oral findings

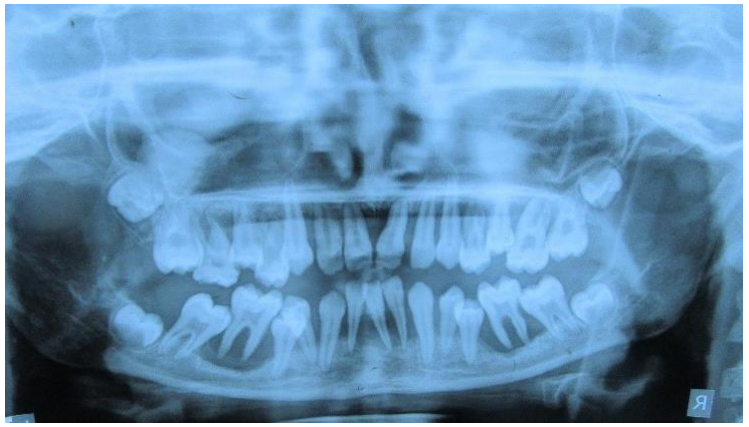

Fig. 3: Orthopantomogram

\section{Dental treatment protocol for patient with PLS. ${ }^{6}$}

Parental counselling and motivation plays a major role in the treatment plan. Hence, in the beginning the patient's parents were counselled about the course of the disease and its outcome. The following treatment plan was followed-

1. Patient was explained Modified bass brushing technique. Then, oral prophylaxis in the form of supragingival and subgingival scaling under local anesthesia was performed. This procedure was repeated every month for continues 3 months with regular follow up to evaluate the periodontal status.

2. Patient was instructed to use of $5 \mathrm{ml}$ of $0.2 \%$ Chlorhexidine gluconate mouthrinse twice daily for 2 mins for initial 15 days.

3. Desensitizing toothpaste containing Strontium chloride and fluoride was prescribed for the patient.

4. Teeth with advanced periodontal disease, 36 and 46 were extracted. 
5. Remaining teeth were maintained with regular oral prophylaxis every three month and regular follow up visits.

Dermatological management- Patient was referred to a dermatologist for the dermatological treatment which included-Acitretin (oral retinoid). The skin lesions gradually increased during winter season. The oral retinoids drastically improved the dermatological lesions with 10 weeks.

Recall after 1 month: There was marked reduction in the gingival inflammation. However the bleeding on probing was still present in the mandibular anterior teeth region. The mobility of teeth was still the same. [Fig. 4 a,b,c]

Recall after 6 month: The gingiva colour changed to pale pink. There was absence in the gingival bleeding. The mobility of teeth was reduced and the patient was able to chew properly. [Fig.5 a,b,c ]

Recall after 12 months-The periodontal and dental condition was stable. [Fig. 6 a,b,c ]

Recall after 3 years: The periodontal and dental condition was stable. [Fig. 7,8]

Future perspective: Implant supported prosthesis in case of edentulism at later age of life.
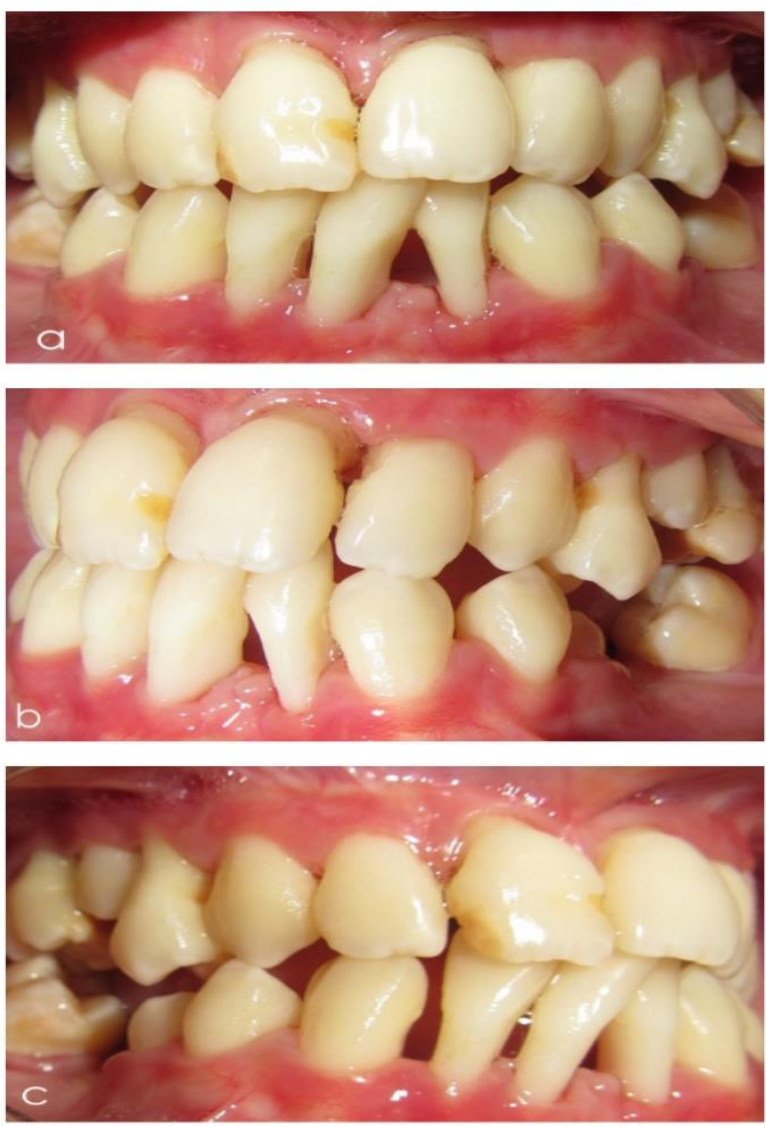

Fig. 4: Recall after 1 month
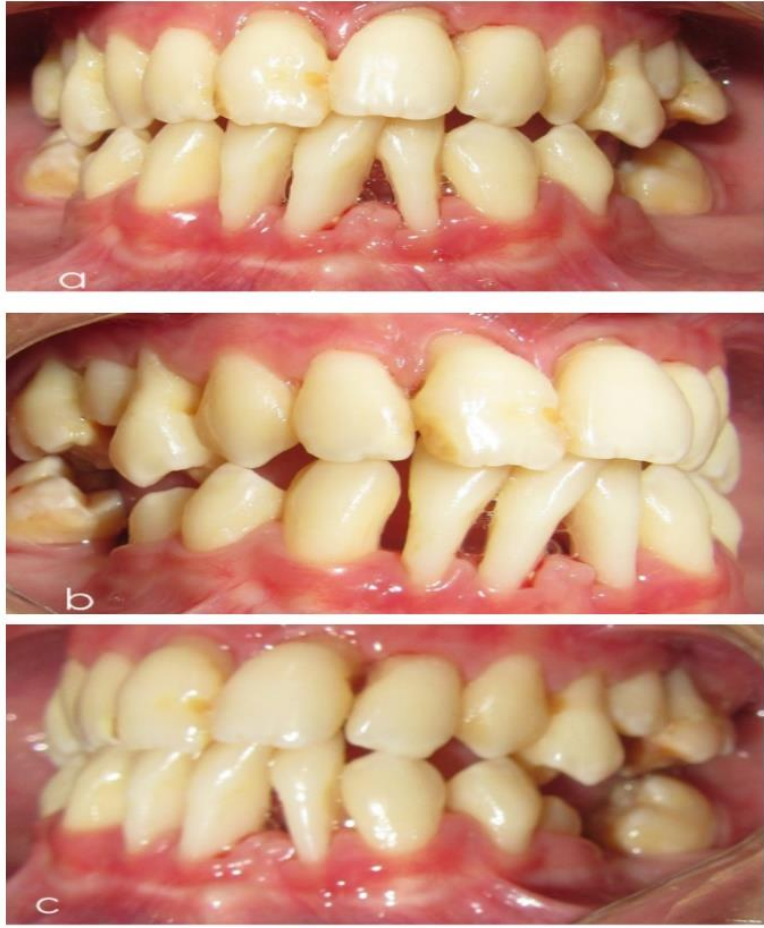

Fig. 5: Recall after 6 months
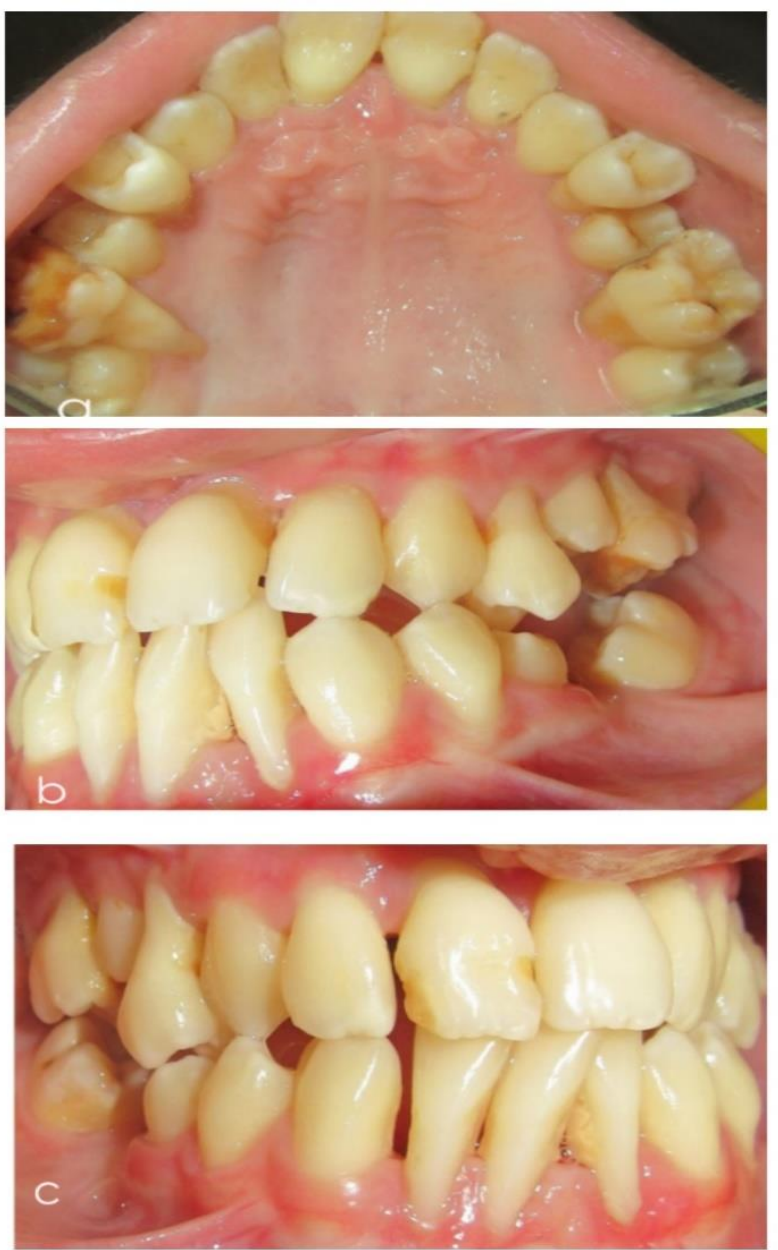

Fig. 6: Recall after 12 months 


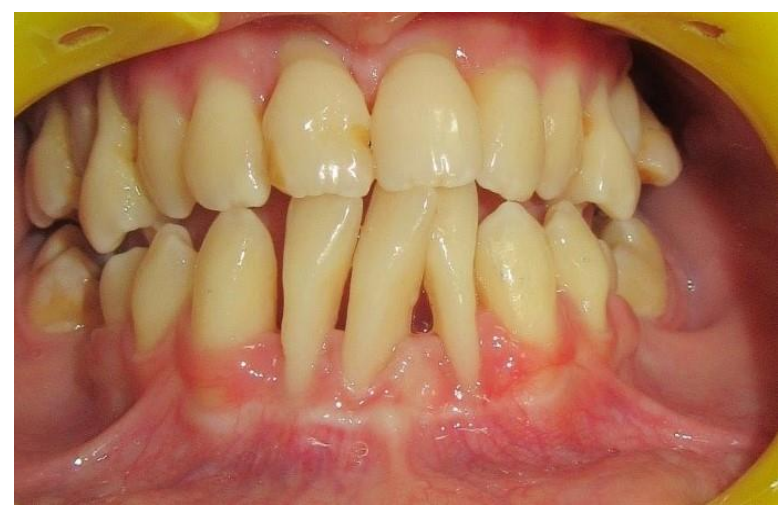

Fig. 7: Recall after 3 years

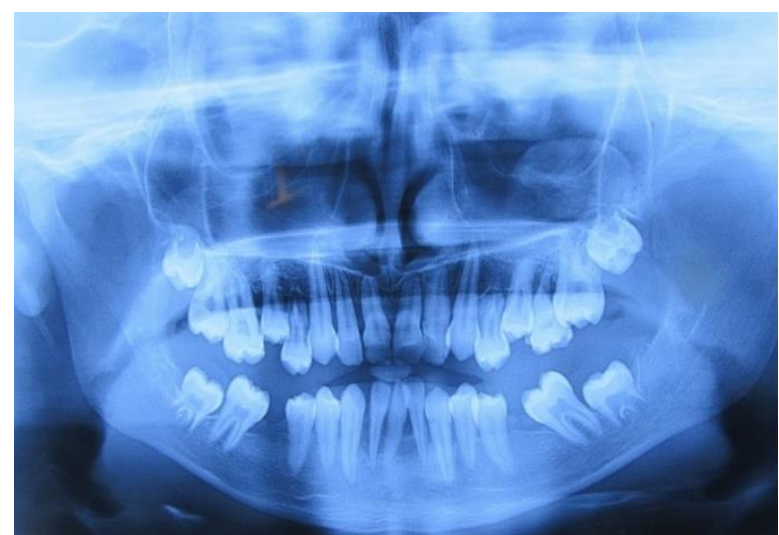

Fig. 8. Orthopantomogram after 3 years

\section{Discussion}

Haneke et al (1979) gave important criterias to identify the cases of Papillon Lefèvre syndrome-“(a) Palmoplantar hyperkeratosis; (b) Loss of primary and permanent teeth; and (c) Autosomal recessive inheritance". 9 The pathophysiology of Papillon Lefèvre Syndrome is associated with several factors.

\section{Genetic factors}

The Cathepsin C (CTSC) gene encodes a cysteine-lysosomal protease. This enzyme is also known as dipeptidyl-peptidase I. The function of dipeptidyl-peptidase $\mathrm{I}$ is to remove dipeptides from the amino terminus of the protein substrate. Mutations of Cathepsin C (CTSC) gene leads to deficiency of CTSC enzymatic activity. ${ }^{10-12}$

\section{Immunologic factors}

CTSC encodes variety of serine protease enzymes. Serine protease enzymes play a major role in variety of inflammatory and immune responses. Hence, deficiency of CTSC function makes an individual immunocompromised, leading to increased susceptibility towards various infection. Latest reports by Lundgren et al (2005) stated that the impairment of natural killer cell cytotoxic function is the first consistent immune dysfunction in PLS. ${ }^{13,14}$

\section{Microbiologic factors}

Various studies were done to prove the microbiological etiological factor involved in the origin of PLS. Robertson et al (2001), found different periodontologic pathogens like A. actinomycetemcomitans, Porphyromonas gingivalis, and Prevotella intermedia in the subgingival plaque of PLS patients. ${ }^{15}$ Albandar (2015) conducted a detailed study of the subgingival microbiota of Papillon-Lefèvre syndrome and detected 12 bacterial species. Cultures of the periodontal pocket samples showed high percentage of A. actinomycetemcomitans colonies. ${ }^{16}$

\section{Differential diagnosis}

Hypophosphatasia, Langerhan's cell histiocytosis, ChediakHigashi syndrome, Acrodynia, Acatalasia, Leukemia and Neutropenia. ${ }^{17}$

Table 1: Literature review on its management

\begin{tabular}{|c|c|c|c|}
\hline S.No & Year & Author & Treatment protocol \\
\hline 1. & 1989 & Kellum RE et al ${ }^{18}$ & $\begin{array}{l}\text { 1. Scaling and root planning; Oral hygiene instructions and } 0.2 \% \\
\text { chlorhexidine gluconate mouth rinses; } \\
\text { 1. Antibiotic treatment therapy in order to control the bacteremia. } \\
\text { 2. Antibiotics: Amoxicillin }(20-50 \mathrm{mg} / \mathrm{kg} / \mathrm{d}) \text { plus metronidazole }(15-35 \\
\mathrm{mg} / \mathrm{kg} / \mathrm{d}) \text {. Amoxicillin and Clavulanic acid was also found effective in } \\
\text { few cases. }\end{array}$ \\
\hline 2. & 1993 & Eronat et al. ${ }^{19}$ & $\begin{array}{l}\text { Amoxicillin plus Clavulanic acid at a dosage of } 1 \mathrm{~g} \text { per day for } 10 \text { days } \\
\text { every } 6 \text { months. }\end{array}$ \\
\hline 3. & 1995 & $\begin{array}{l}\text { Baer and Mcdonald et } \\
\mathrm{al}^{20}\end{array}$ & $\begin{array}{l}\text { 1. It was suggested to extract all primary teeth till the age of } 3 \text { years. } \\
\text { 2. Removable prosthesis after } 3 \text { month. } \\
\text { 3. Therapeutic dose of tetracycline for } 10 \text { days after placement of the } \\
\text { dentures; }\end{array}$ \\
\hline 4. & 1995 & Kressin $\mathrm{S}$ et $\mathrm{al}^{21}$ & $\begin{array}{l}\text { Treatment modalities such as systemic and local antibiotic treatment, and } \\
\text { synthetic retinoids have been tried with limited success }\end{array}$ \\
\hline 5. & 2002 & Herrera et $\mathrm{al}^{22}$ & $\begin{array}{l}\text { Scaling and root planning along with adjunctive antibiotics in combination } \\
\text { with adequate home care is effective in improving the clinical periodontal } \\
\text { parameters. }\end{array}$ \\
\hline 6. & 2005 & Jain V.Gupta et $\mathrm{al}^{23}$ & $\begin{array}{l}\text { It was suggested to replaced by removable prosthesis during mixed } \\
\text { dentition phase. Later on, after the eruption of permanent teeth various } \\
\text { other treatment modalities were used to replace the missing teeth like }\end{array}$ \\
\hline
\end{tabular}




\begin{tabular}{|l|l|l|l|}
\hline & & & $\begin{array}{l}\text { conventional complete dentures, modified complete conventional } \\
\text { complete dentures, modified complete dentures, implant supported } \\
\text { complete dentures, over dentures, or a combination of these. }\end{array}$ \\
\hline 7. & 2005 & Lee MR et al ${ }^{24}$ & $\begin{array}{l}\text { Prolonged use of oral retinoids has been shown to be beneficial in } \\
\text { preventing exfoliation of permanent teeth in children }\end{array}$ \\
\hline 8. & 2005 & Ullbro C et al $^{25}$ & $\begin{array}{l}\text { Dermatological lesions were treated by oral administration of Retinoids } \\
\text { specifically Acitretin and Etretinate. }\end{array}$ \\
\hline 9. & 2011 & Ahmadian et al ${ }^{26}$ & $\begin{array}{l}\text { Implant-supported overdentures were recommended for the oral } \\
\text { rehabilitation of edentulous patients with PLS. }\end{array}$ \\
\hline 10. & 2014 & Teughels W et al. ${ }^{27}$ & $\begin{array}{l}\text { Surgical treatment of such aggressive form of periodontal cases is } \\
\text { generally not supported by a lot of studies. }\end{array}$ \\
\hline
\end{tabular}

\section{Conclusion}

Under the limitations of this case report, we draw the following conclusions:

1. Edentulism at a young age may have psychological as well physiological impact on children. That's why it is very important to preserve the compromised dentition in such patients.

2. Proper treatment protocol helps to achieve long term preservation of teeth in patients with Papillon Lefèvre syndrome.

3. Parent counselling plays a very important role in the treatment plan.

\section{Source of funding}

None.

\section{Conflict of interest}

None.

\section{References}

1. Gorlin RJ, Sedano H, Anderson VE. The syndrome of palmarplantar hyperkeratosis and premature periodontal destruction of the teeth. A clinical and genetic analysis of the PapillonLefèvre syndrome. J Pediatr 1964;65:895-908.

2. Papillon MM, Lefèvre P. Two cases of family symmetrical keratoderma palmar and plantar (disease of Meleda) in the brother and the sister. Coexistence in both cases of serious dental deteriorations. Bull Soc Fr Dermatol Syphiligr 1924;31:82-7.

3. Cury VF, Costa JE, Gomez RS, Boson WL, Loures CG, De ML. A novel mutation of the cathepsin C gene in PapillonLefèvre syndrome. J Periodontol 2002;73:307-12.

4. Khan FY, Jan SM, Mushtaq M. Papillon-Lefèvre syndrome: Case report and review of the literature. J Indian Soc Periodontol 2012;16(2):261-5.

5. Hart TC, Shapira L. Papillon-Lefèvre syndrome. Periodontol 2000;1994;6:88-100.

6. Ullbro C, Crossner CG, Nederfors T, Alfadley A, ThestrupPedersen K. Dermatologic and oral findings in a cohort of 47 patients with PapillonLefèvre syndrome. J Am Acad Dermatol 2003;48(3):345-51.

7. Kanthimathinathan HK, Browne F, Ramirez R, McKaig S, Debelle G, Martin J, Chapple IL, Kay A, Moss C. Multiple cerebral abscesses in Papillon-Lefèvre syndrome. Childs Nerv Syst 2013;29(8):1227-9.

8. Hart TC, Hart PS, Bowden DW. Mutation of the cathepsin C gene are responsible for Papillon-Lefèvre syndrome. $J$ Med Genet 1999;36:881-7.
9. Haneke E. The Papillon-Lefèvre syndrome: keratosis palmoplantaris with periodontopathy. Human Genetics 1979;51:1-35.

10. Angel TA, Hsu S, Kornbleuth SI, Kornbleuth J, Kramer EM. Papillon-Lefevre syndrome: a case report of four affected siblings. J Am Acad Dermatol 2002;46:S8S10.

11. Nagy N, Valyi P, Csoma Z, Sulak A, Tripolszki K, Farkas K. CTSC and Papillon-Lefevre syndrome: detection of recurrent mutations in Hungarian patients, a review of published variants and database update. Mol Genet Genomic Med 2014;2(3):21728. doi:101002/mgg361 Epub 2014 Feb 11

12. Turk D, Janjic V, Stern I, Podobnik M, Lamba D, Dahl SW, et al. Structure of [9] human dipeptidyl peptidase I (cathepsin C): exclusion domain added to an endopeptidase framework creates the machine for activation of granular serine proteases. EMBO J 2001;20(23):6570-82

13. Lundgren T, Parhar RS, Renvert S, Tatakis DN. Impaired cytotoxicity in Papillon-Lefèvre syndrome. J Dent Res 2005;84:414-7.

14. de Haar SF, Hiemstra PS, van Steenbergen MT, Everts V, Beertsen W. Role of polymorphonuclear leukocyte-derived serine proteinases in defense against Actinobacillus actinomycetemcomitans. Infect Immun 2006;74:5284-91

15. Robertson KL, Drucker DB, James J, Blinkhorn AS, Hamlet S, Bird PS. A microbiological study of Papillon-Lefevre syndrome in two patients. J Clin Pathol 2001;54(5):371-6.

16. Albandar JM, Khattab R, Monem F, Barbuto SM, Paster BJ. The subgingival microbiota of Papillon-Lefevre syndrome. $J$ Periodontol 2012;83(7):902-08.

17. Glenwright HD, Rock WP. Papillon-Lefèvre syndrome. A discussion of aetiology and a case report. British Dental Journal 1990; 168: 27-29.

18. Kellum RE. Papillon-Lefèvre syndrome in four siblings treated with Etretinate. A nine-year evaluation. Int J Dermatol 1989;28:605-8.

19. Eronat N, Ucar F, Kiline G. Papillon-Lefèvre syndrome: Treatment of two cases with a clinical microbiological and histopathological investigation. J Clin Pediatr Dent 1993; 17:99-104.

20. Baer PN, McDonald RE. Suggested mode of periodontol therapy for patients with Papillon-Lefèvre syndrome. Periodont Case Rep 1981;1:10

21. Kressin S, Herforth A, Preis S, Wahn V, Lenard HG. PapillonLefèvre syndrome - successful treatment with a combination of retinoid and concurrent systematic periodontal therapy: case reports. Quintessence Int 1995;26(11):795-803.

22. Herrera D, Sanz M, Jepsen S, Needleman I, Roldan S. A systematic review on the effect of systemic antimicrobials as an adjunct to scaling and root planing in periodontitis patients. J Clin Periodontol 2002:29(Suppl 3):136-59.

23. Jain V, Gupta R, Prakash H. Prosthodonti rehabilitation in PapillonLefevre syndrome: a case report. J Indian Soc Pedod Prev Dent 2005;23(2):96-98. 
24. Lee MR, Wong LC, Fischer GO. Papillon-Lefèvre syndrome treated with acitretin. Australas J Dermatol 2005;46(3):199 201.

25. Ullbro C, Brown A, Twetman S. Preventive periodontal regimen in Papillon-Lefèvre syndrome. Pediatr Dent 2005;27:226-32.

26. Ahmadian L, Monzavi A, Arbabi R, Hashemi HM. Full-mouth rehabilitation of an edentulous patient with Papillon-Lefèvre syndrome using dental implants: a clinical report. $J$ Prosthodont 2011;20(8):643-8.
27. Teughels W, Dhondt R, Dekeyser C, Quirynen M. Treatment of aggressive periodontitis. Periodontol 2014:65:107-33.

How to cite this article: Lashika V Tambe, Mala Dixit, Nikita Patil. Papillon lefevre syndrome- A literature review and case report. Int J Periodontol Implantol 2019;4(3):107-12. 